\title{
Peritonite infecciosa felina: 13 casos
}

\author{
Feline infectious peritonitis: 13 cases
}

\author{
Fabiano Nunes de Oliveira ${ }^{1}$ Margarida Buss Raffi $^{2}$ \\ Tatiana Mello de Souza ${ }^{3}$ Claudio Severo Lombardo de Barros ${ }^{4}$
}

\section{RESUMO}

Numa pesquisa realizada em tecidos de 638 gatos necropsiados, foram encontrados 13 casos $(2,03 \%)$ de peritonite infecciosa felina. Oito desses casos $(61,53 \%)$ eram da forma efusiva ou úmida, e 5 apresentavam a forma seca ou não-efusiva da doença. A idade dos gatos afetados variou de 2 meses a 3 anos. Doze gatos (92,30\%) eram de raças puras, cinco deles (38,47\%) eram oriundos de ambientes onde havia mais de um gato e três eram provenientes de um mesmo gatil. A duração da doença clínica foi de 7 a 45 dias e os sinais clínicos incluíram emagrecimento, anorexia, diarréia, icterícia, vômito, linfadenopatia e distúrbios neurológicos. Os achados de necropsia na forma úmida incluíam excesso de líquido viscoso (50ml a 1 litro), translúcido ou levemente opaco na cavidade peritoneal e, em um caso, na cavidade torácica. Exsudato fibrinoso cobria as superfícies serosas dos órgãos abdominais dando-lhes aspecto granular e brancacento. Na forma seca, havia múltiplos focos granulomatosos sob a superficie serosa e para o interior do parênquima de órgãos abdominais; esses achados eram particularmente proeminentes nos rins. Opacidade de córnea foi observada em um gato. Histologicamente, havia graus variáveis de vasculite e perivasculite piogranulomatosa, particularmente em arteriolas. Meningite ou meningoencefalite piogranulomatosa foram observadas em três gatos com a forma seca de peritonite infecciosa felina.

Palavras-chave: peritonite infecciosa felina, doenças de gatos, doenças a vírus, coronavírus, patologia.

\section{ABSTRACT}

In a survey carried out in tissue specimens from 638 necropsied cats, 13 cases (2.03\%) of feline infectious peritonitis were found. Eight of those (61.53\%) were of the effusive or wet form and five had the dry non-effusive form of the disease. Ages of affected cats varied from 2-months to 3 yeas. Twelve affected cats (92.30\%) were purebreds, five of these cats $(38.47 \%)$ came from households with more than one cat and three of them came from the same comercial cat raising facility. The duration of clinical courses were 7-45 days and clinical signs included loss of weight, anorexia, diarrhea, jaundice, vomiting, swollen lymph nodes, and neurological disturbances. Necropsy findings, in the wet form included excess of yellowish viscous tanslucent or slightly opaque fluid $(50 \mathrm{ml}-$ 1 liter) in the peritoneal cavity and (in one case) thoracic cavity. Fibrinous exudate covered the serosal surfaces of abdominal organs imparting a whitish, granular, frost-like appearance to them. In the dry form there were multiple granulomatous foci underneath the serosal surface, which extended into the parenchyma of abdominal organs; these findings were particularly prominent in the kidneys. Corneal opacity was observed in one cat. Histologically, there were variable degrees of disseminated piogranulomatous vasculitis and perivasculitis particularly in arterioles. Pyogranulomatous meningitis or meningoencephalitis were observed in three cats with the dry form of feline infectious peritonitis.

Key words: feline infectious peritonitis, diseases of cats, viral diseases, coronavirus, pathology.

\section{INTRODUÇÃO}

A peritonite infecciosa felina (PIF) foi descrita pela primeira vez na década de 60 e, desde então, foram relatados casos em felinos domésticos e selvagens em todo o mundo (HOSKINS \& LOAR, 1993; McREYNOLDS \& MACY, 1997). O agente etiológico foi identificado como um coronavírus,

${ }^{1}$ Estudante do $10^{\circ}$ semestre de Medicina Veterinária da Universidade Federal de Santa Maria (UFSM), bolsista de Iniciação Científica $\mathrm{PIBIC} / \mathrm{CNPq}$.

${ }^{2}$ Médico Veterinário, Mestre, aluno do Programa de Pós-graduação em Medicina Veterinária, área de Patologia Veterinária, UFSM.

${ }^{3}$ Medico Veterinário, Bolsista de Apoio Técnico, CNPq, junto ao Departamento de Patologia, UFSM.

${ }^{4}$ Médico Veterinário, PhD., Professor Titular do Departamento de Patologia, UFSM, 97105-900, Santa Maria-RS. E-mail:

barroscs@lince.hcv.ufsm.br. Autor para correspondência. 
denominado de vírus da peritonite infecciosa felina (FIPV), que é uma mutação do coronavírus entérico felino (FECV) (ADDIE \& JARRET, 1998). Esse vírus infecta macrófagos e a infecção é, às vezes, ajudada pelo conceito da intensificação dependente de anticorpo, na qual a presença de imunoglobulinas contra o FECV, aumenta a entrada do vírus em macrófagos, pela ligação do complexo antígenoanticorpo ao receptor FC (BRAUND, 1994; MURPHY et al., 1998).

A PIF é uma enfermidade imunomediada, sistêmica, progressiva e fatal que se tornou importante para veterinários que atendem gatos que vivem em densidades populacionais altas dessa espécie (ADDIE \& JARRET, 1998) pois nesses ambientes há uma prevalência maior da doença, em parte devido à maior contaminação viral e aumento do número de cepas do FIPV, expondo os animais a altas doses infectivas nas fezes (FOLEY et al., 1997). A ocorrência é também maior em gatos jovens. Outros fatores que influenciam o aparecimento da PIF são estresse, susceptibilidade genética, doenças intercorrentes, via de infecção e imunocompetência mediada por células (HOSKINS \& LOAR, 1993).

A doença é classificada em formas efusiva (úmida) e não-efusiva (seca), com base na quantidade de derrame cavitário (ascite ou hidrotórax) (ADDIE \& JARRETT, 1998). Uma forma incomum da PIF afeta focalmente o íleo, a junção ileocecocólica ou o cólon e linfonodos adjacentes (HARVEY et al., 1996; ADDIE \& JARRETT, 1998). Histologicamente, a PIF consiste de uma inflamação predominantemente piogranulomatosa localizada ao redor de vasos, principalmente de vênulas (BARKER, 1993; JONES et al., 2000, STORTS \& MONTGOMERY, 2000).

Este artigo descreve a prevalência, os dados epidemiológicos, os sinais clínicos, as lesões macro e microscópicas dos casos de peritonite infecciosa felina (PIF) diagnosticados pela Seção de Patologia Veterinária da Universidade Federal de Santa Maria (SPV/UFSM).

\section{MATERIAL E MÉTODOS}

Os arquivos do SPV/UFSM, entre 1970 a 2001, foram revisados. Foram anotados o número de exames histopatológicos e necropsias realizadas em gatos e o número de gatos com diagnóstico de PIF. Desses últimos, foram relacionados idade, sexo, raça, histórico clínico e procedência. Os sinais clínicos e as lesões macro e microscópicas, foram revisados. Dependendo da quantidade de derrame cavitário, a doença foi classificada como efusiva ou não-efusiva.

\section{RESULTADOS}

Entre 1970 e 2001, foram examinados histologicamente tecidos provenientes de necropsias de 638 gatos. Desses, 13 animais necropsiados $(2,03 \%)$ tiveram o diagnóstico de PIF. A idade, o sexo, a raça, a procedência, a forma da doença e os sinais clínicos apresentados pelos gatos afetados constam na tabela 1. A faixa etária dos gatos afetados variou de 2 meses a 3 anos. Oito casos $(61,53 \%)$ apresentaram a forma efusiva e cinco $(38,47 \%)$ a forma não-efusiva. A maioria dos gatos afetados $(69,23 \%)$ era macho, cinco gatos $(38,47 \%)$ provinham de ambiente onde havia mais de um gato e três desses eram oriundos de um mesmo gatil. Doze gatos $(92,30 \%)$ tinham raça definida e a evolução clínica esteve entre 7 e 45 dias. Onze animais $(84,61 \%)$ tiveram morte espontânea, e os restantes foram submetidos à eutanásia devido ao mau estado e à ineficácia dos tratamentos. A análise do líquido ascítico, realizada apenas no gato $\mathrm{n} ¹$, revelou exsudato asséptico rico em neutrófilos.

Os achados de necropsia dos oito gatos com a forma efusiva incluíam peritonite fibrinosa e ascite. $\mathrm{O}$ volume desses derrames variou de $50 \mathrm{ml}$ até aproximadamente um litro, e eram amarelados, translúcidos ou levemente opacos, viscosos e, em alguns casos, continham filamentos de fibrina. $\mathrm{O}$ acúmulo de líquido causava distensão indolor ao abdome. Quando exposto ao ar, o líquido coagulava rapidamente (Figura 1). Um exsudato branco acinzentado recobria todas as superfícies serosas, conferindo-lhes aspecto granular. Isso era particularmente marcante sobre o fígado, baço e intestinos (Figura 2), e, em menor intensidade, sobre o omento, bexiga, parede abdominal, pâncreas e estômago. Em um gato afetado havia pequena quantia de derrame semelhante na cavidade torácica.

Em dois gatos dos cinco com a forma nãoefusiva, não foram observadas alterações macroscópicas; os outros três apresentavam focos inflamatórios granulomatosos multifocais de intensidade variável localizados sob a serosa dos órgãos da cavidade abdominal e se estendiam ao parênquima subjacente. Essa lesão era mais pronunciada nos rins e seguia o trajeto dos vasos. Em um dos gatos, havia opacidade de córnea do olho esquerdo.

Histologicamente, as principais alterações consistiam de graus variáveis de perivasculite e vasculite piogranulomatosas, principalmente em arteríolas e veias de pequeno calibre em diversos órgãos. Nos casos da forma efusiva, havia também peritonite fibrinosa. Meningite e meningoencefalite 
Tabela 1 - Casos de peritonite infecciosa felina diagnosticados no Setor de Patologia Veterinária da Universidade Federal de Santa Maria.

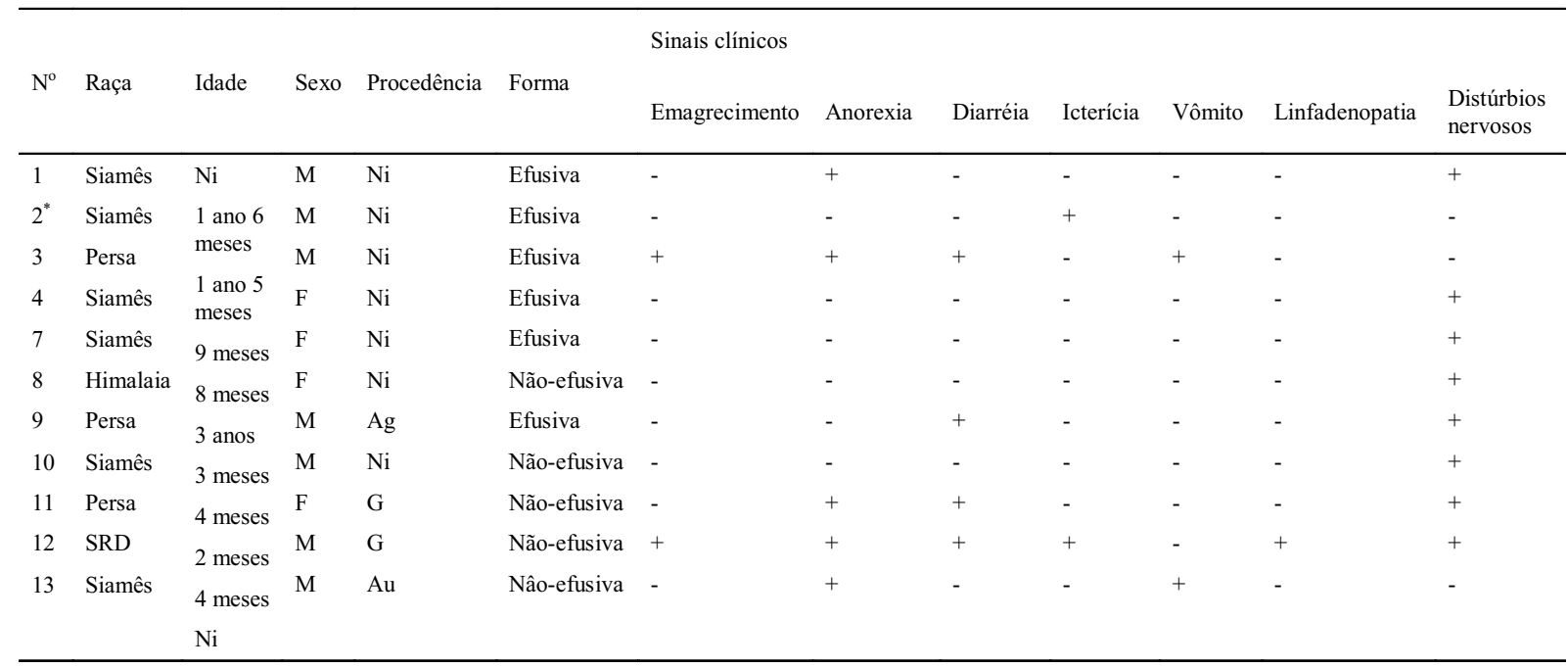

Obs.: No caso dos Gatos 5 e 6 , os sinais clínicos não foram informados.

$\mathrm{Ni}=$ Não informado

$\mathrm{F}=$ Fêmea

$\mathrm{M}=$ Macho

$\mathrm{G}=$ Gatil

$\mathrm{Ag}=$ Ambiente com mais de um gato

$\mathrm{Au}=$ Ambiente com um único gato

= Material positivo para antígeno do coronavírus felino através de imuno - histoquímica pelo método complexo peroxidase avidina - biotina.

piogranulomatosas foram vistas em três gatos que desenvolveram a forma não-efusiva.

\section{DISCUSSÃO}

O diagnóstico, nesses 13 casos, foi baseado nas lesões macro e microscópicas que são consideradas diagnósticas (BARKER, 1993; JONES et al., 1997), ou altamente sugestivas (PEDERSEN, 1995) de PIF. Em um caso, o diagnóstico foi adicionalmente confirmado pela técnica de imuno-histoquímica ${ }^{a}$.

A faixa etária de todos os casos desse estudo ( 2 meses a 3 anos) é descrita, por outros autores como a faixa etária ( 3 meses a 3 anos) de maior ocorrência para a PIF (McREYNOLDS \& MACY, 1997; ADDIE \& JARRETT, 1998). No entanto, podem ocorrer casos em gatos com mais de 10 anos, associados ao declínio da resposta imune relacionada à idade (McREYNOLDS \& MACY, 1997; STORTS \& MONTGOMERY, 2000). Neste estudo, foi observado um maior número de casos em gatos machos (69,23\%). Esse dado é difícil de interpretar porque não se sabe o sexo dos gatos da população $(n=638)$ examinada e não se pode excluir que os machos estivessem representados em maior número nessa população. Os dados de literatura são também conflitantes neste aspecto; alguns mencionam a maior incidência de PIF em machos não castrados (ROHRBACH et al., 2001) e outros afirmam que não há diferença na distribuição da doença entre os sexos (FOLEY et al., 1997).

A constatação de que, em 5 casos, os gatos provinham de ambiente onde havia mais de um gato, sendo 3 desses de um mesmo gatil, corrobora a afirmação de que, nesses ambientes, a ocorrência de PIF é maior devido ao favorecimento da transmissão fecal-oral pelo aumento da contaminação viral (FOLEY et al., 1997). A manutenção de gatos portadores crônicos que eliminam o vírus através das fezes, e a consangüinidade entre os animais com maior número de indivíduos geneticamente susceptíveis à doença, também explicam a ocorrência mais freqüente da enfermidade em gatis. Num gatil desse estudo, havia relatos anteriores de casos de PIF em animais da mesma linhagem. A possibilidade do desenvolvimento de PIF em gatos que vivem sozinhos, como ocorreu neste estudo, não é descartada pelos autores (ADDIE \& JARRETT, 1998).

Há uma prevalência maior de PIF em gatos de raça pura, porém nenhuma raça tem mostrado uma predisposição para a doença; nesse estudo apenas um animal não era de raça pura. Um aumento da susceptibilidade ou diminuição da resistência à PIF, ocorre em algumas populações de gatos com alta consangüinidade. Por outro lado, gatos de raças puras

Ciência Rural, v. 33, n. 5, set-out 2003. 


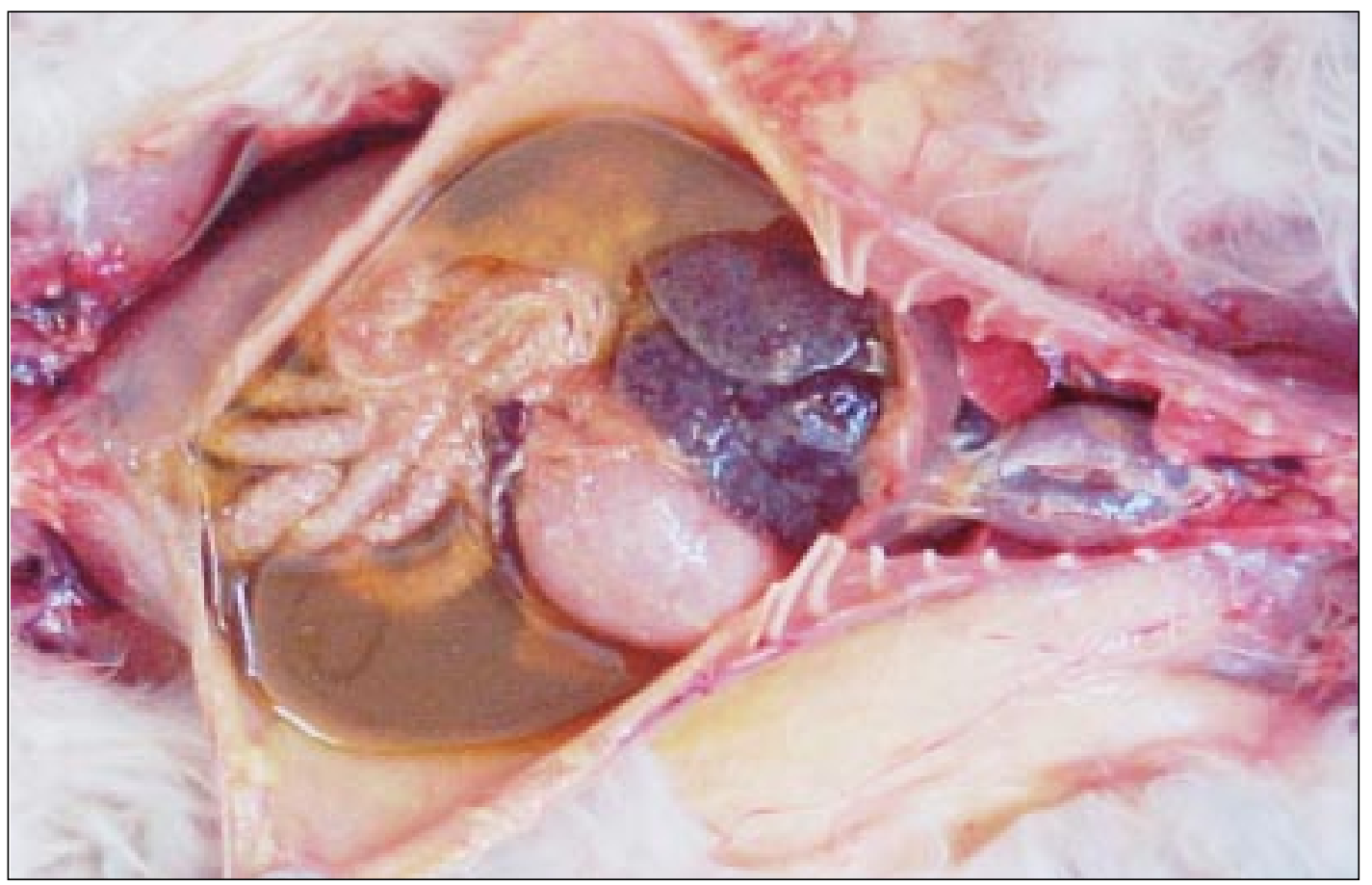

Figura 1 - Peritonite infecciosa felina. Coleção de líquido amarelado, viscoso e contendo fibrina na cavidade abdominal do Gato 9.

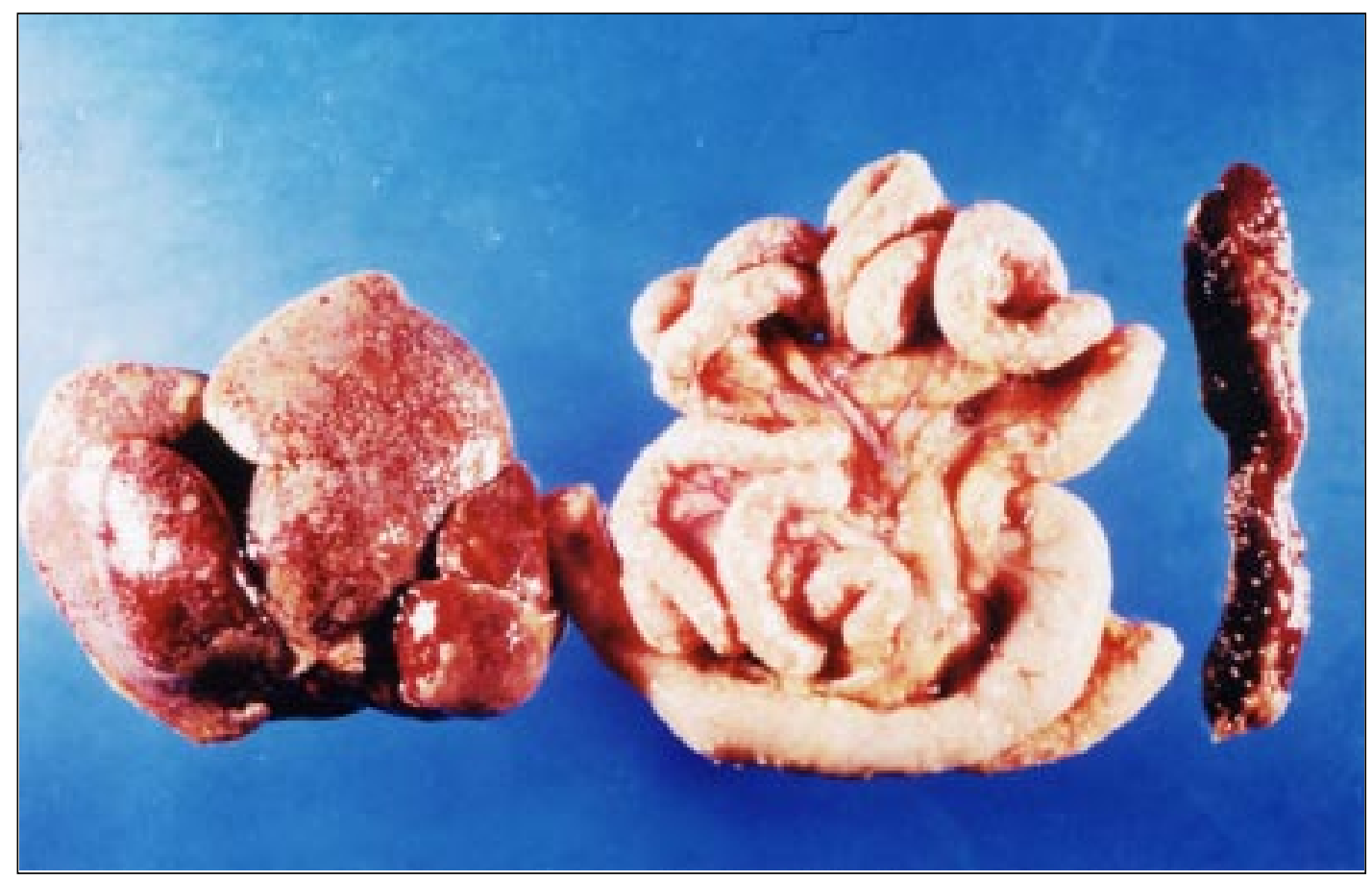

Figura 2 - Peritonite infecciosa felina. Gato 9. Exsudato fibrinoso recobrindo as serosas do baço (à esquerda), intestino e fígado. Nódulos granulomatosos multifocais são observados na serosa intestinal.

Ciência Rural, v. 33, n. 5, set-out 2003. 
provavelmente provêm de gatis com grande número de animais, o que pode predispor o aparecimento da doença (ROHRBACH et al., 2001). Episódios de estresse, como desmame, transporte, cirurgias, doenças intercorrentes e procedimentos veterinários parecem ser importantes no desenvolvimento da PIF (PEDERSEN, 1995; McREYNOLDS \& MACY, 1997; ADDIE \& JARRETT, 1998).

A evolução dos sinais clínicos até a morte nos gatos deste estudo foi 7 a 45 dias. Na maioria dos relatos, a doença evolui para morte em 1 a 12 semanas, com a maioria dos gatos morrendo 2 meses após o início dos sinais clínicos (McREYNOLDS \& MACY, 1997). A mortalidade de ambas as formas é de aproximadamente 100\% (BARKER, 1993).

Aproximadamente $75 \%$ dos casos clínicos de PIF são da forma efusiva e ocorrem em gatos com forte resposta imune humoral (RIH) e pouca ou nenhuma resposta imune celular (RIC). A forma nãoefusiva se manifesta quando o animal gera uma RIH associada a uma RIC parcial (BRAUND, 1994; EVERMANN et al., 1995). Neste estudo, a taxa de prevalência da forma efusiva foi de $61,53 \%$ contra $38,47 \%$ da forma não-efusiva. Os sinais clínicos observados em seis gatos deste estudo são semelhantes aos descritos na literatura, tanto para a forma efusiva como para a forma não-efusiva (McREYNOLDS \& MACY, 1997; ADDIE \& JARRETT et al., 1998).

Os gatos deste estudo, classificados como na forma efusiva, apresentaram acúmulo de líquido viscoso, amarelo e opaco nas cavidades abdominal ou torácica, acompanhado por distensão abdominal indolor. Essas alterações são descritas na literatura em associação à forma efusiva da PIF (HOSKINS \& LOAR, 1993; McREYNOLDS \& MACY, 1997; ADDIE \& JARRETT, 1998; TASKER \& GUNNMOORE, 2000). Além dessas, em casos de PIF são descritos massas perceptíveis à palpação abdominal, edema escrotal, vários níveis de dispnéia com padrão respiratório restrito e ruídos cardíacos abafados em gatos com derrame pleural (HOSKINS \& LOAR, 1993; McREYNOLDS \& MACY, 1997; ADDIE \& JARRETT, 1998). Esses últimos não foram observados nos gatos deste levantamento talvez por falta de exame clínico mais detalhado.

$\mathrm{Na}$ forma não-efusiva, as manifestações clínicas dependem dos órgãos afetados e geralmente são pouco definidas (HOSKINS \& LOAR, 1993; McREYNOLDS \& MACY, 1997; ADDIE \& JARRETT, 1998). Gatos com essa forma geralmente apresentam lesões oculares (McREYNOLDS \& MACY, 1997; ADDIE \& JARRETT, 1998), principalmente irite, caracterizada por mudança na coloração da íris (ADDIE \& JARRETT, 1998). Um gato deste estudo tinha opacidade no olho esquerdo, mas a natureza histológica da lesão não foi determinada.

Até $30 \%$ dos animais com PIF têm envolvimento do sistema nervoso central (SNC). As lesões consistem de vasculite por deposição de imunocomplexos. Adicionalmente, há falha na RIC em destruir o vírus, resultando em múltiplos granulomas formados por macrófagos infectados no interior do SNC. Sinais clínicos de distúrbios neurológicos são mais freqüentes na forma não-efusiva, e mesmo gatos sem déficits neurológicos podem apresentar lesões microscópicas inflamatórias no SNC. Os sinais clínicos mais freqüentes são paresia dos membros pélvicos, ataxia generalizada, hiperestesia toracolombar, nistagmo, anisocoria, mudanças no comportamento, apreensão, tetraparesia e tremores (BRAUND, 1994). Quando a doença causa meningite, os sinais clínicos (por ex., incoordenação, tremores, hiperestesia, mudanças de comportamento, apreensão e febre sem uma causa aparente) refletem danos ao tecido nervoso subjacente (ADDIE \& JARRET, 1998). Além das meninges, o plexo coróide e o epêndima (McREYNOLDS \& MACY, 1997) podem ser afetados e causar obstrução ocasional do aqueduto mesencefálico, resultando em hidrocefalia (SUMMERS et al., 1995), que pode ser diagnosticada por radiologia ou tomografia computadorizada (ADDIE \& JARRET, 1998).

Neste estudo, dos oito animais que manifestaram sinais clínicos neurológicos, quatro não tiveram lesões microscópicas no SNC que explicassem os prováveis sinais clínicos associados à doença. Dois animais, que desenvolveram a forma não-efusiva, não tinham histórico de distúrbios neurológicos mas apresentaram, histologicamente, meningoencefalite características da PIF. Outros dois animais com distúrbios neurológicos apresentaram meningoencefalite piogranulomatosa no exame histológico.

Os derrames pleural e peritoneal possuem alta concentração de proteínas (McREYNOLDS \& MACY, 1997; TASKER \& GUNN-MOORE, 2000) com grande percentual de globulinas (SHELLY et al., 1988; SPARKES et al., 1994), celularidade relativamente baixa para um exsudato (McREYNOLDS \& MACY, 1997), com predominância de neutrófilos (PEDERSEN, 1995; McREYNOLDS \& MACY, 1997), monócitos e macrófagos (PEDERSEN, 1995). O líquido é comumente amarelo, pode conter filamentos de fibrina (McREYNOLDS \& MACY, 1997) e é classificado 
como exsudato asséptico, por apresentar neutrófilos não degenerados e ausência de bactérias (TASKER $\&$ GUNN-MOORE, 2000). No único gato deste estudo, em que foi realizada a análise do líquido peritoneal, foram encontradas as características descritas na PIF.

O diagnóstico na PIF pode ser difícil por causa da variabilidade das manifestações clínicas e do tempo de incubação (EVERMANN et al.,1995), mas, em muitos casos, pode ser feito através da avaliação do histórico, achados clínicos, resultados laboratoriais, título de anticorpos para coronavírus e exclusão de doenças semelhantes (HOSKINS \& LOAR, 1993; EVERMANN et al.,1995). A avaliação da efusão tem grande importância no diagnóstico presuntivo de PIF (ADDIE \& JARRETT, 1998), no entanto, o diagnóstico definitivo é feito através da necropsia e histopatologia (BARKER, 1993).

Os achados de necropsia e histopatológicos deste estudo estão de acordo com o que é descrito por BARKER (1993), JONES et al. (2000), GELBERG, (2000) e STORTS (2000) para a doença, porém a separação das formas clínicas baseada na extensão e distribuição dos derrames cavitários é arbitrária (BARKER, 1993).

A forma não-efusiva deve ser diferenciada de linfossarcoma multicêntrico, esteatite, infecções micóticas e toxoplasmose. A forma efusiva da doença deve ser diferenciada de peritonite bacteriana, piotórax (BARKER, 1993), colangite linfocítica, doença cardíaca, neoplasias (linfoma hepático, esplênico ou alimentar), doença renal e hepática, pancreatite, esteatite e obstrução da veia cava caudal (TASKER \& GUNN-MOORE, 2000). Não há tratamento eficaz, a maioria das terapias é baseada em cuidados de suporte, incluindo reposição de fluídos e nutrientes. A principal conduta é o uso tópico ou sistêmico de corticoesteróides (BRAUND, 1994).

A PIF não é controlada facilmente, requer a eliminação do vírus do ambiente, através de alto padrão de higiene, quarentena, medidas imunoprofiláticas (MURPHY et al., 1998) e, principalmente, manejo dos gatinhos filhos de mães soropositivas para coronavírus felino (FCoV) (ADDIE \& JARRETT, 1998), que devem ser desmamados precocemente para interromper a transmissão viral (BRAUND, 1994). Uma vacina com vírus vivo modificado protege gatos com títulos baixos ou ausentes para FcoV e, em alguns gatos, a vacina falha provavelmente devido à infecção preexistente (BRAUND, 1994). Uma excelente revisão das medidas de prevenção da doença foi publicada recentemente (ADDIE \& JARRETT, 1998).

\section{FONTES DE AQUISIÇÃO}

a - Realizado por D. Haines, Veterinary Diagnostic Services, Western College of Veterinary Medicine, University of Saskatoon, Saskatchewan, Canadá.

\section{REFERÊNCIAS BIBLIOGRÁFICAS:}

ADDIE, D. D.; JARRETT, O. Feline coronavirus infection. In: GREENE, C. E. Infectious diseases of the dog and cat. Athens, Georgia : Saunders, 1998. Cap.11. p.58-69.

BARKER, I.K. The peritoneum and retroperitoneum. In: JUBB, K.V.F.; KENNEDY, P.C.; PALMER, N. Pathology of domestic animals. San Diego : Academic, 1993. V.2. Cap.4, p. $425-445$.

BRAUND, K.G. Neurological diseases. In: BRAUND, K.G. Clinical syndromes in veterinary neurology. St. Louis: Mosby, 1994. Cap.3, p.81-333.

EVERMANN, J.F.; HENRY, C.J.; MARKS, S.L. Feline infectious peritonitis. Journal American Veterinary Medical Association, v.206, n.8, p.1130-1134, 1995.

FOLEY, J. E. et al. Risk factors for feline infectious peritonitis among cats in multiple-cat environments with endemic feline enteric coronavirus. Journal of American Veterinary Medical Association, v. 210, n. 9, p. 1313-1318, 1997.

GELBERG, H. B. Alimentary system. In: CARLTON, W. W., McGAVIN, M. D. Thomson's special veterinary pathology. St. Louis: Mosby, 2000. Cap. 1. p.1-79.

HARVEY, C. J., LOPEZ, J. W., HENDRICK, M. J. An uncommon intestinal manifestation of feline infectious peritonitis: 26 cases (1986-1993). Journal American Veterinary Medical Association, v.209, n.6, p.1117-1120, 1996.

HOSKINS, J.D.; LOAR, A.S. Feline infectious diseases. Veterinary Clinics of North America, v.23, n.1, p.2-11, 1993.

JONES, T.C., HUNT, R.D., KING, N.M. Diseases caused by viruses. In: Veterinary pathology. Baltimore : Williams \& Wilkins, 1997. Cap.8, p.197-370.

McREYNOLDS, C.; MACY, D. Feline infectious peritonitis. Part I. Etiology and diagnosis. Compendium Continuing Education of the Practicing Veterinarian, v.19, n.9, p.10071012, 1997.

MURPHY, F.A. et al. Veterinary virology. San Diego: Academic, 1999. 629p.

PEDERSEN N.C. An overview of feline enteric and infectious peritonitis virus infectious. Feline Practice, v.23, n.3, p.720, 1995 .

ROHRBACH, B.W. et al. Epidemiology of feline infectious peritonitis among cats examined at veterinary medical teaching hospitals. Journal American Veterinary Medical Association, v.218, n.7, p.1111-1115, 2001. 
SPARKES, A.H.; GRUFFYDD-JONES, T.J.; HARBOUR, D.A. An appraisal of the value of laboratory tests in the diagnosis of feline infetious peritonitis. Journal of the American Animal Hospital Association, v.30, p.345-349, 1994.

STORTS, R.W.; MONTGOMERY, D.L. The nervous system. In: CARLTON, W.W.; McGAVIN, M.D
Thomson's special veterinary pathology. St. Louis : Mosby, 2000. Cap.8,p.435-436.

SUMMERS, B.A.; CUMMINGS, J.F.; LAHUNTA A. Veterinary neuropathology. St. Louis : Missouri, Mosby, 1995. 527p.

TASKER, S.; GUNN-MOORE, D. Differential diagnosis of ascites in cats. In Practice, v.22, n.8, p.472- 479, 2000. 